\title{
Atividades direcionadas para turmas de Educação Infantil: uma experiência estética e filosófica da arte para um aprendizado das "emoções democráticas"
}

\section{Activities aimed at kindergarten classes: an aesthetic and philosophical experience of Arts for learning "democratic emotions"}

Amélie Lila Merle defendeu seu doutorado em Ciências da Educação na Université Lumière Lyon 2 em 2017. Hoje é professora temporária da mesma instituição.

\section{Resumo}

0 presente artigo propõe analisar o uso da arte e da filosofia em práticas educativas com crianças pequenas. A análise diz respeito a uma atividade específica realizada em duas turmas de Educação Infantil. 0 corpus é composto por transcrições das falas das crianças e observações feitas nas duas turmas. Como resultado, conclui-se que uma formação ou um ensino que tenha características singulares colabora para o desenvolvimento de competências e habilidades das crianças; habilidades tanto intelectuais quanto emocionais. Palavras-chave: Arte. Filosofia. Experiência. Emoções democráticas. Empatia.

\footnotetext{
Abstract

The aim of this paper is to analyze the use of Arts and Philosophy in educational practices with young children. This analysis focuses on a specific activity implemented in two kindergarten classes. The corpus analyzed consists of transcriptions of the children's speeches and observations made in both classes. As a result, this analysis shows that a training which has unique characteristics contributes to the development of children's intellectual and emotional skills. Key words: Arts, Philosophy. Experience. Democratic emotions. Empathy.
} 


\section{Introdução}

0 objetivo deste texto é compreender de que modo as práticas artísticas aliadas às práticas filosóficas podem resultar em um modelo de prática democrática. Mais especificamente, considerase a arte um modelo de prática democrática (DEWEY, 1934; ZASK, 2007) e uma experiência do mundo (CHIROUTER, 2015; MERLE, 2017).

Atualmente, as práticas educativas, até mesmo as que se direcionam às crianças menores, fazem uso, ao mesmo tempo, da arte e da filosofia. A questão que se coloca pode ser formulada da seguinte maneira: Por que fazer tal uso? Quais são os motivos para essa prática conjunta?

A hipótese seria a de que tal aproximação se inscreve em uma concepção educativa que não limita a formação do cidadão à sua dimensão intelectual, mas o considera também em sua dimensão emocional.

Martha Nussbaum (2011) defende que o desenvolvimento da empatia no sujeito não é algo inato e que o ideal é ensiná-la às crianças o mais cedo possível. Isso se tornaria possível graças a um aprendizado das "emoções democráticas" (NUSSBAUM, 2011). A empatia pode ser criada, aprendida e depois vivenciada pelas crianças por meio de uma experiência estética artística, pela colaboração e pelas trocas proporcionadas pelos ateliês de artes.

Buscando fundamentar essa ideia, propomos analisar uma atividade realizada durante um ano escolar com criançasde 4 e 5 anos frequentadores da Educação Infantil. ${ }^{1} 0$ objetivo é mostrar que seria possível ensinar emoções democráticas por meio da experiência e da prática da arte e da filosofia.

\section{0 problema e sua origem}

\section{Referências na origem desta pesquisa}

Como assinala Edwige Chirouter, há quarenta anos a filosofia tem sido ensinada para crianças ao redor do mundo. A arte tem ocupado da mesma forma um bom espaço nas escolas e, desde 1983, algumas atividades como aulas com projetos artísticos e culturais e iniciativas ligadas à educação artística e cultural (como a PEAC) ${ }^{2}$ ou, ainda, residências de artistas têm sido cada vez
1. Nota do tradutor: 0 sistema de ensino francês propõe o início da escolarização aos 3 anos de idade. A primeira etapa de escolarização é dividida na pequena seção, para os iniciantes, a seção intermediária para as crianças de 4 anos e a grande seção para crianças de 5 anos; a pesquisa é realizada nas salas destas duas últimas seções. Esta etapa é denominada Maternelle, aqui traduzida como Educação Infantil.

2. Nota do tradutor: O PAEC, o Percurso (ou trajetória) de Educação Artística e Cultural (Parcours d'éducation artistique et Culturelle), é o conjunto de conhecimentos, de práticas experimentais e de encontros realizados no campo das artes e do patrimônio. Estabelecido por lei, este percurso deve ser ministrado durante toda a educação básica e tem o objetivo de favorecer o acesso de todos os alunos à arte e à construção de uma cultura artística pessoal. Decidimos neste texto utilizar o termo "percurso" corresponder com a sigla do dispositivo. 
mais comuns. Em vista de tais práticas, pode-se avaliar agora, já com o distanciamento suficiente e necessário, os seu efeitos em termos de aprendizado, mas também o que está em jogo em uma avaliação da Educação Artística e Cultural (BORDEAUX e KERLAN, 2016).

Pretende-se buscar novos ângulos de leitura para a questão ao se perguntar por que recorrer à arte e à filosofia no trabalho com crianças, ou seja, quais são os motivos, em vez de se questionar "como" e "em que medida".

De acordo com Nussbaum (2011), a busca pelas humanidades é um tipo de resposta a uma crise que atravessa a educação e que, por sua vez, resulta de uma crise mais ampla da cultura tal como identificada por Arendt. Segundo Nussbaum, uma educação voltada exclusivamente para o lucro não favorece o desenvolvimento e nem a existência de condições que permitam o funcionamento das sociedades democráticas. Seria possível, além do mais, se interrogar acerca das condições necessárias para que a democracia possa existir.

Nussbaum propõe um modelo de educação voltado para a democracia - Education for Democracy - e para um aprendizado das emoções democráticas.

\section{As emoções democráticas}

Tais emoções seriam emoções voltadas para o outro e para a existência de cada um. Porém, como não são emoções inatas, elas devem ser ensinadas e obtidas por meio de um ensino específico. As emoções democráticas podem ser obtidas sob determinadas condições, por exemplo, no encontro com o outro e na experiência com o outro. Nussbaum considera que uma cultura de emoções voltada para o "humano" seria a condição necessária para a vida democrática, motivo pelo qual aborda as "humanidades" como condição para o desenvolvimento do que ela chama de "capabilidades". Segundo a pesquisadora, esse termo incluiria a capacidade de cada indivíduo ultrapassar o plano individual para ir em direção ao outro, mas, também, a capacidade de imaginar e adotar um pensamento crítico. E, além disso, a capacidade de pensar no outro com empatia.

Por que a educação deveria propor uma Education for Democracy? A democracia exige dos cidadãos que tenham uma participação ativa, que sejam independentes no modo de refletir e 
capazes de pensar criticamente e refletir de modo a criar relações entre cada um. É nesse sentido que se encaminha a ideia de Nussbaum de capabilities. 0 termo destaca que todo indivíduo possui as capacidades necessárias para se tornar um cidadão, e que ele pode cumprir isso se lhe forem ofertados, por meio da educação, os recursos e meios para aprender as emoções e, sobretudo, criar a empatia necessária para o reconhecimento do outro.

0 ser humano pensa com os seus sentidos e ag'e em função daquilo que vai sentir. As percepções de uma situação real vão possibilitar ao indivíduo agir de forma consciente em seu meio. Cada ação do sujeito é guiada por uma reflexão acerca da situação, por uma percepção de tal situação e pelas emoções que ela vai despertar.

Para agir de modo consciente as crianças vão aprender a sentir emoções e ser capazes de ter uma experiência com o outro. Vão aprender a estar no mundo e descobrir a si mesmas. As emoções democráticas devem nascer da experiência (DEWEY, 1981) que pode ser definida como uma interação entre os seres e o seu meio, uma atividade reflexiva, que mistura os sentidos, a percepção e a ação. A experiência oferece a possibilidade de encontro com o próximo. Ao ler um livro ou observar uma obra de arte, a criança se encontra com um autor, um artista, um universo artístico. Encontrar-se com a cultura do outro, com a experiência da pluralidade, é um aprendizado fundamental para as crianças e isso Ihes trará elementos para que ocupem um lugar no mundo quando se tornarem adultas.

\section{Questões de pesquisa}

Se a educação busca unicamente lucrar, ela não vai permitir que se estabeleçam as condições favoráveis às sociedades democráticas. As Humanidades constituiriam uma ferramenta para possibilitar o estabelecimento de tais condições favoráveis. De acordo com Nussbaum, seria possível aprender as emoções democráticas por meio da experiência com a arte. De que maneira e por que a arte poderia possibilitar às crianças o aprendizado das emoções?

Os trabalhos de Winnicott (2002) destacam o papel essencial da arte na criação de um espaço de jogo, espaço tal que permite se situar em relação ao outro e desenvolver um imaginário. A literatura, a ficção, é igualmente um meio de viver a experiência do 
outro, de entrar em um mundo imaginário, de criar empatia pelos personagens ou pelo autor. A literatura seria dotada de uma função referencial, ou seja, uma função que permite elucidar o real. A literatura, a ficção, é um tipo de "laboratório" (RICOEUR, 1990) que propõe uma experiência da realidade. Ela constitui uma concepção singular da prática artística considerada, deste modo, como uma ferramenta de abertura e conhecimento do mundo e do outro, mas também de si mesmo. A arte dá a ver a alteridade pois permite um reconhecimento de si no outro quando ocorre uma identificação com os personagens, com o autor, com o artista. Além disso, a arte permitiria reconhecer "a si mesmo como uma outra pessoa". (RICOEUR, 1990)

De acordo com Nussbaum e com Chirouter, essa capacidade de se colocar no lugar do outro é essencial nas sociedades multiculturais. 0 desejo de viver em conjunto 3 pode nascer de uma consideração pelo outro, de um reconhecimento do outro.

Será que o uso da arte com crianças pequenas pode ser compreendido como um meio de criar uma das condições favoráveis para o funcionamento da sociedade democrática?

0 ponto de partida desta reflexão considera que as práticas da arte e da filosofia fornecem as condições favoráveis para o desenvolvimento das emoções na criança e que a busca das humanidades está ligada a um desejo de dar uma formação intelectual e emocional aos futuros cidadãos.

Nussbaum (2011) privilegia três princípios para efetivar o ensino das emoções democráticas:

1. A prática do debate vai ao encontro de uma prática que Chirouter (2015) defende que seja difundida e que consiste na criação de oficinas de filosofia para as crianças. É uma forma de pedagogia chamada "socrática", isto é, uma educação em que a reflexão, o espírito crítico, nasce da prática do diálogo e das trocas. Ao exercitar o pensamento crítico, o indivíduo pode ter acesso à vida democrática. Graças a um aprendizado das emoções democráticas, tais como a empatia, o indivíduo seria mais livre para pensar, para tomar iniciativas, para agir como indivíduo consciente e independente.

2. A preocupação de formar cidadãos do mundo dialoga com a visão de uma sociedade multicultural aberta para o mundo. A educação deve formar "um representante ativo, crítico, reflexivo e que tenha empatia por uma comunidade de
3. N. do T.: Em francês, vivre ensemble, expressão utilizada no discurso político e midiático que significa viver harmoniosamente em sociedade. 
iguais" (NUSSBAUM, 2011, p. 154). Para tanto, a criança deve, desde muito cedo, estar em relação com o outro, aprender a raciocinar, argumentar e refletir com o outro.

3. Impulsionar o imaginário das crianças pequenas com ajuda da literatura e da arte tem o objetivo de ajudar a desenvolver as emoções infantis. Sobre o tema, Nussbaum trata da imaginação narrativa, que seria a "capacidade de imaginar o que aconteceria se uma pessoa estivesse no lugar da outra, interpretando de forma inteligente a história dela, compreendendo as emoções, vontades e desejos que ela poderia sentir" (2011, p. 121). É interessante lembrar a importância das emoções no desenvolvimento afetivo e cognitivo da criança. A literatura e a arte vão propor uma experiência à criança: uma experiência rica de ensinamentos sobre como obter capacidades afetivas e efetivas. Em outras palavras, depois de viver certas emoções na leitura de livros ou em uma prática artística, a criança estará em condições de agir e refletir de forma mais livre sobre situações concretas que ela precisa enfrentar.

Esse terceiro princípio se revela particularmente elucidativo no que diz respeito ao encaminhamento da presente pesquisa e do objeto do estudo, ou seja, o uso da arte nas práticas educativas para crianças pequenas.

Construiu-se o problema a partir de uma constatação que pode ser formulada da seguinte maneira: as práticas educativas, direcionadas até mesmo às crianças menores, fazem uso, ao mesmo tempo, da arte e da filosofia. Por que utilizar tal recurso hoje em dia?

A hipótese proposta aqui se fundamenta sobre a tese defendida por Nussbaum (2011):

Essa aproximação, ou seja, o uso conjunto da arte e da filosofia, se inscreve em uma concepção educacional que não se limita à formação do cidadão em sua dimensão unicamente intelectual, mas o considera também em sua dimensão emocional.

Pensando nos futuros cidadãos, é preciso uma formação voltada para as emoções. A arte e a filosofia se mostram como recursos favoráveis para o aprendizado das emoções. Os debates e as práticas da literatura e da arte serviriam como ferramentas. A formação voltada para as emoções seria facilitada pelo fato de que cada indivíduo tem a capacidade de pensar livremente. 0 método 
consistiria, assim, em estimulá-lo mais do que ensinar a ele as "capabilidades".

Segundo os resultados de uma pesquisa anterior sobre a prática de apresentar livros de artistas para as crianças (MERLE, 2017), fica claro que, ao ter um contato regular com obras de arte e/ou com um artista, a criança desenvolve mais facilmente habilidades no domínio da linguagem, da expressão e do raciocínio, mas igualmente outras habilidades, como trabalhar em grupo, colaborar com o outro, envolver-se em uma atividade coletiva.

No que diz respeito às emoções, e sobretudo à empatia, é preciso observar as interações entre pares, a natureza e o teor das trocas feitas, mas também a postura das crianças no espaço de criação. 0 que elas dizem umas para as outras? Como se colocam no grupo? Conseguem se comunicar entre elas? São respeitosas umas com as outras? Ao surgirem conflitos, como fazem para administrá-los?

Além disso, procuramos também examinar o desenvolvimento das emoções ao longo de um tempo, isto é, verificar se uma prática regular com obras de arte permitiria de fato uma melhora na relação das crianças com os outros e com o mundo. Como a sociedade está voltada para um modelo multicultural, a criança, para existir, pensar e agir de maneira plenamente consciente, deve estar dotada de tais "capabilidades". E é por meio da experiência das emoções que ela pode desenvolver essas faculdades.

A seguir, um desdobramento das indagações iniciais: quais habilidades devem ser desenvolvidas para que os indivíduos sejam capazes de refletir de modo adequado sobre os problemas que são colocados aos cidadãos? Como as pessoas adquirem a capacidade de ter respeito e igualdade democráticas?

A resposta formulada por Nussbaum (2011) se apoia no fato de que o indivíduo tem a necessidade de aprender a refletir livremente, de aprender também emoções, como a empatia, para lidar melhor com o mundo. 0 essencial é que ele seja capaz de compreender situações concretas, de compreender outro indivíduo que não ele próprio e "se colocar no lugar do outro". 


\section{Abordagem metodológica, atividade proposta, análise e discussão}

\section{A atividade}

A atividade experimental foi posta em prática em duas turmas diferentes de infantil. Essa precaução nos permitiu manter um distanciamento da atividade para poder observar com o máximo de objetividade e disponibilidade. A escola selecionada é uma escola primária particular ${ }^{4}$, mas conveniada com o governo, situada perto do subúrbio da cidade de Lyon.

As turmas de maternal e infantil são compostas por três séries: os pequenos ( 3 anos), os médios ( 4 anos) e os grandes (5 anos). A experiência foi realizada unicamente com crianças do infantil, de 4 e 5 anos, totalizando 56 crianças.

As sessões propostas, sejam oficinas de filosofia ou workshops artísticos, duravam 30 minutos.

Os encontros eram semanais, com duas sessões por semana, durante todo o ano escolar. 0 objetivo não era fazer as crianças filosofarem como fazem os alunos do terceiro ano do ensino médio se tornarem artistas. A intenção era apresentar a elas um universo de pensamento e uma prática artística específica.

As sessões respeitavam um protocolo que foi utilizado nas duas turmas observadas:

- uma leitura inicial feita pelo professor (10 minutos)

- um workshop artístico (30 minutos)

- um debate filosófico (30 minutos)

- acesso livre à obra na biblioteca

\section{Ferramentas para o registro dos dados}

Durante as sessões foram realizadas gravações em áudio. 0 material registrado permitiu uma análise das trocas realizadas e dos comportamentos dos alunos. 0 conjunto dessas trocas foi transcrito. A seguir encontram-se trechos que respeitam a cronologia das sessões e servem para a identificação de posturas, papéis assumidos pelos alunos e interações entre pares, seja nos workshops artísticos, seja nas oficinas de filosofia.
4. Embora o termo esteja em desuso na sociedade brasileira, ele é adequado na sociedade francesa. A escola primária agrupa a Educação Infantil (École Maternelle) e a escola elementar (École Élémentaire), que recebe crianças de 6 a 11 anos. 
0 modelo criado por Filiod (2014) de sensível-comoconhecimento (2014) pareceu interessante para esta pesquisa já que permite modalizar a relação que o indivíduo mantém com as percepções do seu meio, seu corpo e seus sentidos.

Esse modelo nos possibilitou questionar as dicotomias clássicas segundo as quais as ciências seriam racionais e a arte apenas subjetiva. Filiod propõe, com a ajuda desse modelo, transformar um conceito abstrato em uma realidade concreta e observável. Esse modelo permitiu observar comportamentos e atitudes e conhecer os laços entre uma prática artística e o desenvolvimento das emoções.

Como sugere a metodologia de Filiod (2014), seria apropriado elaborar uma grade de observação a partir de treze categorias (SOBHANE, 2012, p. 10), divididas em duas grandes seções: as relativas à postura e as da linguagem.

Entre as 13 categorias propostas pelo grupo de pesquisa coordenado por Jean-Paul Filiod, mantivemos 5:

- A curiosidade das crianças, medida a partir das perguntas ou reações de cada uma durante o tempo do workshop.

- A concentração das crianças, medida a partir do tempo que a criança passa na atividade.

- A relação das crianças umas com as outras, a interação entre pares.

- A construção dos argumentos e da linguagem de cada criança, por meio de uma análise do discurso.

- A relação com o mundo, avaliada por uma análise do uso de pronomes pessoais.

Para facilitar nossas observações, pareceu necessário nos concentrar nos comportamentos e posturas dos alunos divididos em subcategorias: os que só observam, os colaboradores, os atentos, os que ordenam, os seguidores ou os decididos.

A linguagem utilizada por cada criança será outro elemento a ser levado em conta, com atenção especial ao vocabulário das emoções, como por exemplo: "eu gosto", "eu não gosto", "eu não entendo", "eu não sei", "que bonito", "que esquisito", "me dá medo" etc. 
Por fim, para interpretar as interações, analisaremos não só as atitudes das crianças, como também o uso de pronomes pessoais. 0 "eu" denota um comportamento de quem "decide" mas é igualmente uma marca de tomada de posição forte, até de poder. 0 "nós" indicaria um desejo de colaboração, uma tomada de consciência do outro.

\section{Análise}

\section{Sobre as práticas artísticas}

De modo geral, os alunos foram receptivos aos ateliês artísticos propostos. É comum a prática de artes plásticas nessa escola em turmas de infantil. Nas turmas mais velhas, atividades como as PEAC estão no centro do projeto do estabelecimento. Mas a presente ação propunha a cada criança, primeiro, conhecer um livro de artista e, depois, realizar o seu próprio, não "ao modo de", mas de forma mais livre, com as ferramentas e materiais de sua escolha. Foi apresentada à turma, por exemplo, a obra Cent milles petits points, do artista Mauro Bellei. Trata-se de um livro de artista que trabalha essencialmente com texturas.

Para o ateliê, as crianças tinham à sua disposição pedrinhas, outro material bastante utilizado pelo artista. Elas puderam, assim, fazer a experiência do universo do artista proposto em Cent mille petits points experimentando outro material.

Essa possibilidade resultou em esculturas, além de discursos interessantes como o seguinte: "Mas o artista não usa pedrinhas neste livro. Como vamos fazer o trabalho?" Ao que outro aluno respondeu: "Bom, é para isso que a gente vai pesquisar". Nessa conversa, o primeiro aluno se pergunta sobre como resolver o seu problema, que podemos resumir brevemente do seguinte modo: 0 artista utiliza texturas, eu só tenho pedrinhas, como fazer? 0 aluno se encontra, assim, em um processo reflexivo e faz a pergunta a outro aluno. Este último responde usando o pronome "on" ["a gente"], indicando que ele certamente vai ajudar o primeiro a resolver o problema. Nos fatos observados, o segundo aluno ajudou o primeiro e eles criaram juntos uma produção plástica.

Houve outras trocas que se relacionam às posturas dos alunos. Alguns alunos que chamamos de "decididos" com frequência assumiam a fala e circulavam entre os pequenos grupos que se formaram de modo natural e livre pelos próprios alunos. É o caso, 
por exemplo, do aluno que interroga outro sobre como organizar pedrinhas para representar o mato: "O que é isso aqui? Mato? Mas o mato é reto e não caído!" A resposta foi imediata e bastante certeira: "Eu sei, mas eu quis fazer assim!" 0 aluno "decidido" se ajoelha ao lado dele e busca um consenso. 0 outro escuta as colocações do primeiro e depois busca justificar o seu próprio ponto de vista. Esse exemplo não é um caso único. Ao longo de toda a ação, foram observadas situações diferentes em que a interação entre pares foi satisfatória e nas quais pudemos distinguir os alunos "decididos" dos "seguidores", que vão atrás dos primeiros, os alunos que ficam observando ou, ao contrário, os que entram em um processo de colaboração, os "colaboradores". Além disso, ficou claro que se o "decidido" assume desde o início uma postura ao mesmo tempo de escuta e de tomar iniciativas, ele terá que agir deste modo durante todo o ano escolar para que alguns "seguidores" ousem tomar decisões e buscar um consenso com os outros.

Também cabe destacar que o vocabulário das emoções se afinou ao longo das sessões. Nos primeiros encontros, era possível ouvir "Eu gosto, eu não gosto, não é bonito". Aos poucos, essas crianças pequenas passaram a formular suas emoções de modo mais pessoal e sofisticado.

Transcrevemos, por exemplo, uma reflexão que constitui uma fina metáfora dita por Marie acerca do trabalho de Noémie: "suas pedrinhas arrumadas assim lembram uma banana e é bonita a banana, é gostosa e bonita". Ou, ainda, outro diálogo:

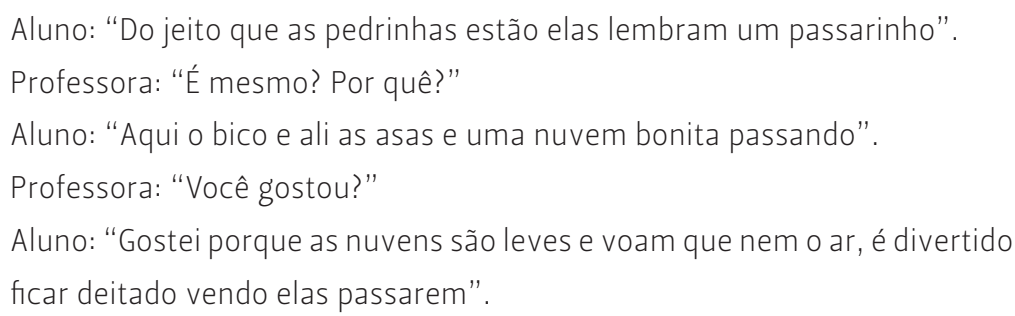

Pode ser que a experiência das pedrinhas repercuta no aluno alguma experiência vivida por ele no passado, talvez a de uma tarde em que ficou deitado na grama observando as nuvens. Esse fenômeno remete "à poética da obra" $(E C O, 1962)$ e à ideia de que o artista recorre à referência e à sugestão para despertar emoções no espectador da obra. Em outras palavras, a obra é concebida pelo artista de modo a comunicar elementos que despertem uma emoção relacionada a um acontecimento vivido pelo espectador no passado. Deste modo, a compreensão e a recepção da obra são mais imediatas. 


\section{Sobre as oficinas de filosofia}

As conversas registradas nas oficinas de filosofia permitiram criar relações com uma prática de debates que visa a formação emocional e, mais especificamente, um aprendizado das emoções democráticas. 0 objetivo final desse processo é criar empatia, princípio preconizado por Nussbaum (2011).

Os alunos foram convidados a "filosofar", no sentido proposto por Edwige Chirouter (2015) que consiste em aprender a se interrogar, a se perguntar o porquê das grandes questões existenciais e a se colocar no debate iniciado pela professora. 0 protocolo seguia o de Michel Tozzi (2001) quanto à forma.

Os alunos se reuniam em um grupo grande e cada um tinha liberdade de se expressar quando estivesse com o "bastão da fala". Quem não estivesse com ele deveria esperar pela sua vez e, na medida do possível, escutar os outros se expressarem sobre o tema da sessão.

Em geral, a sessão começava com uma pergunta feita pela professora, como: "0 que é a felicidade?" Depois os alunos deviam dar a sua opinião.

No começo do ano, os alunos não estavam familiarizados com o protocolo e, por isso, falavam pouco, às vezes nada. 0 aprendizado da linguagem é um dos princípios básicos na educação infantil. Desde essa etapa de ensino, a criança aprende a conviver coletivamente, a conhecer os seus pares e se comunicar com eles. A linguagem, sob todas as formas, está no centro dos aprendizados dos menores. Na experiência que tivemos, os alunos que falavam faziam uso apenas do "eu" e só raramente ouviam as falas dos outros.

Vemos, por exemplo, Arthur se expressando sobre a felicidade: "Bom, para mim a felicidade é quando eu saio da escola e encontro a minha mãe". Arthur fala de um acontecimento íntimo, emprega o pronome pessoal "eu" e não abre a discussão para outra forma de felicidade possível. Em seguida, o aluno que vai falar pega o bastão da fala com Arthur e diz: "Bom, para mim a felicidade é quando a gente vai à casa do meu primo e a gente brinca". Nesse caso, assim como o anterior, não existe abertura alguma e ele não se refere à fala de Arthur, porém utiliza o pronome pessoal "on" ["a gente"], que inclui seu primo, ainda que não inclua os outros alunos da turma. 
No fim do ano, as crianças trocam ideias com maior respeito pela vez de cada um. Maelys comenta o tema da tristeza: "A tristeza é difícil de expressar... Outro dia na hora do recreio, a gente estava brincando, mas não com Charlotte, e depois ela ficou triste".

Outro aluno fala e complementa a história de Maelys: "É verdade, a tristeza é quando Charlotte não brincou com a gente porque a gente não quis". Depois, outro aluno: "Não é isso a tristeza, a tristeza é quando a gente chora, e Charlotte não chorou". Nesse exemplo, é possível perceber que os alunos se ouvem mais, pois, na sua vez de falar, eles retomam o que foi dito anteriormente pelos colegas, ora para completar a fala deles ou trazer outro olhar sobre a mesma situação, ora para, ao contrário, não concordar e justificar sua própria ideia. Isso pode ser considerado uma marca de progressiva consciência do outro na semelhança, mas também na diferença. A empatia é vivida por meio dessas trocas entre os alunos.

As crianças começam a ouvir umas às outras e constroem juntas uma reflexão, uma argumentação, tentando compreender e tornar real um conceito abstrato.

No que diz respeito às posturas dos alunos, assim como acontece nas oficinas de artes, há os há os "pouco-falantes" que ficam à parte da discussão, os alunos que não participam ou participam pouco da ação. Os motivos podem ser timidez, recusa em expressar seu ponto de vista ou falta de ideia. Em alguns, observa-se um engajamento progressivo ao longo das sessões; já outros demonstram que o exercício continua sendo difícil apresentando dificuldades apesar da frequência semanal dos encontros. Como cada criança tem o seu próprio ritmo de aprendizado, e esse período da educação infantil de preparação dos alunos à escola elementar podendo se estender por uns três anos, supõe-se que essas crianças se revelem posteriormente, nas semanas ou meses seguintes.

As crianças das duas turmas de infantil aproveitaram a atividade proposta para fazer trocas, se construírem e participarem da vida da turma. Foi no período e no espaço do workshop que as crianças que assim quiseram tiveram espaço para compartilhar ideias e criar coletivamente. Cada criação resultante das oficinas artísticas foi exposta e comentada. Por meio de um processo compartilhado, as crianças construíram ideias comuns. Analisando a estrutura das atividades, ou seja, o espaço e o tempo específicos de cada oficina, encontramos a noção de "comum" tal como Joëlle Zask a definiu: 
"O comum aparece como resultado de um processo demorado ao longo do qual as pessoas envolvidas se fazem ouvir, moldam seu ponto de vista de acordo com o modo como os outros expressam o seu próprio, deliberam e afinam as expectativas de cada um" (ZASK, 2007, p. 106).

A noção de comum de Zask traz certo parentesco com a de Nussbaum em Education for Democracy (2011). Ao aprender a ouvir os outros, a compreender as emoções e a sentir empatia pelos outros, formam-se futuros cidadãos.

Algumas crianças não passaram a ter mais concentração e nem melhoraram sua relação com os outros alunos, apesar de terem participado ativamente nas atividades. Mesmo com resultados parciais, cada uma das crianças evoluiu em termos de criação e de curiosidade por práticas culturais. Nas duas turmas, deixamos para livre consulta os livros dos artistas estudados nas sessões. Alguns "pouco falantes" consultaram por vontade própria as obras na biblioteca da turma.

As atividades estimularam produções coletivas e resultaram em pinturas feitas por grupos pequenos de crianças fora do período dos workshops. Em relação aos encontros filosóficos, também observamos progressos na argumentação; a linguagem utilizada passou a ser mais precisa e articulada.

Ao longo das sessões, os alunos ficaram cada vez mais à vontade nas ações dos workshops e encontros. Se, no começo da experiência, as crianças tinham uma representação das coisas que era mais focada em si, no fim, os discursos mostravam uma verdadeira transformação no olhar, que passou a focar mais a obra e nos colegas.

Além disso, as noções de interação e de colaboração começaram a aparecer durante os encontros filosóficos.

Ao fim do estudo, o tempo de fala de cada um passou a ser respeitado, o que não acontecia no começo do experimento. As crianças se esforçavam para ouvir o outro e, em alguns casos, retomavam uma ideia dita anteriormente por um colega para acrescentar alguma nuance. As crianças gostaram das atividades, pois faziam perguntas sobre os debates filosóficos e dividiram suas experiências com a família.

Segundo Roland Barthes, "o mundo está cheio de signos, mas nem todos esses signos têm a bela simplicidade das letras do 
alfabeto" (1964, p. 228). Assim, convém sugerir às crianças formas de se comunicar, de trocar, de se expressar por diferentes meios. Parece que a linguagem plástica permite um acesso mais imediato pois oferece a possibilidade de ultrapassar as barreiras da língua e de seu nível de domínio. Isso permite à criança que ainda não sabe ler aprender o mundo e se comunicar com os colegas de outras maneiras.

A análise do corpus revelou uma relação entre uma prática artística e filosófica e o desenvolvimento da colaboração entre crianças.

\section{Discussões}

As observações permitiram constatar uma maior capacidade de concentração em algumas crianças. E, ao mesmo tempo, um uso mais frequente do "nós" em sua argumentação e raciocínio. 0 uso do "nós" significa que a criança consegue tirar o foco de si para escutar o outro. Podemos ver nesse gesto uma marca de re-conhecimento do outro. Tal constatação vai ao encontro da tese defendida por Nussbaum segundo a qual uma educação voltada para as artes facilita o desenvolvimento da empatia, sentimento necessário para a continuidade e bom funcionamento da democracia.

Por fim, quais são os motivos para o uso da arte nas práticas pedagógicas com crianças?

Um primeiro argumento apresentado é o de que a arte diminui as desigualdades escolares e proporciona a todos o acesso à cultura. A multiplicação de turmas com projeto artístico e cultural, as modificações sucessivas nos programas escolares para dar às artes um lugar mais "nobre", o aumento do número de residências de artistas nas escolas, as pesquisas sobre os efeitos do PEAC (Percurso de Educação Artística e Cultural) são todos sinais que mostram uma profunda vontade de democratizar a arte. Mas não só. Também são muito esperados os resultados de tais práticas no aprendizado dos alunos.

Em suma, a arte proporciona alternativas de ensino justamente naquilo que as outras disciplinas não dão conta. Se é verdade que a arte pode ser terra e adubo que oferece amplas possibilidades para o desenvolvimento das emoções, competências e habilidades necessárias ao aprendizado, não podemos, contudo, negar a contribuição intelectual de outros campos do ensino. 
Um segundo argumento, que parece contradizer o primeiro, diz respeito à busca da autonomia da criança. Seja a autonomia motora da criança, seja em seu modo de pensar. A escola deseja formar futuros cidadãos capazes de pensar por si a fim de serem eficazes e eficientes. A educação voltada para o lucro busca criar rapidamente seres autônomos e produtivos. Mas tal capacidade seria obtida negando, por fim, a existência do outro. Esse modelo de individualização autocentrada se afasta do que foi preconizado por Dewey ao privilegiar a individuação e o pensamento coletivo.

Será que a arte e a filosofia conseguiriam formar emoções democráticas? E, principalmente, o sentimento de empatia?

Nussbaum (2011) afirma que, por meio da prática das Humanities, seria possível mudar o modo como se pensa a educação na democracia. A análise das atividades que fizemos mostrou que, de fato, as crianças desenvolveram emoções relacionadas à empatia. Como no caso da tomada de consciência do outro, observada nos comportamentos das crianças nas oficinas de arte. Elas passaram a se escutar mais, a interagir e a chegar a acordos juntas.

Elas buscaram chegar a um consenso quando um elemento provocava discussões no grupo. E elaboraram estratégias para resolverem juntas o problema, cada uma expondo sua própria ideia. 0 objetivo de "desenvolver a capacidade de prestar atenção de verdade nos outros [...] e promover a responsabilidade ao tratar cada criança como um agente responsável" (NUSSBAUM, 2011, p. 107) parece ter sido alcançado.

Além disso, as atividades revelaram que a criança pode desenvolver a capacidade de tomar consciência do outro por meio do fenômeno da ajuda mútua. Como assinala Nussbaum (2011, p. 29), "uma criança que sabe como se virar sozinha não sente necessidade de submeter as outras". Como consequência, ela é capaz de considerar seu meio como um espaço onde também estão outras pessoas com suas próprias necessidades e seu próprio projeto de vida. Nas oficinas de artes, mas igualmente nos debates filosóficos, ficou evidente o fenômeno da ajuda mútua: as crianças tiravam a atenção de seus próprios problemas para ouvir e respeitar as palavras dos outros. 


\section{Conclusão}

Por meio das atividades propostas, as crianças passam a colaborar, participar coletivamente, trocar, construir raciocínios, aprender a argumentar, seja acerca de suas próprias ideias (nos debates filosóficos) ou dos sentimentos que as atravessam (nos ateliês artísticos). Trata-se de uma formação do espírito, uma formação intelectual e emocional que, segundo Nussbaum (2011), é necessária à continuidade da democracia. Afinal, ser cidadão é ser responsável e estar à escuta dos outros; é saber viver em coletivo com respeito pelo outro, em suas diferenças e semelhanças. É também um modo de aceitar o outro e, ao mesmo tempo, encontrar a si mesmo. De acordo com Nussbaum (2011), a democracia é possível graças a uma tomada de consciência das emoções democráticas, isto é, no sentido em que passamos, de fato, a ser atores na comunidade em que estamos quando temos consciência de que, mais do que um dever, é uma maneira de ser, de sentir a comunidade. A educação que oferece uma formação intelectual e emocional parece ser a condição que permite aos futuros cidadãos que eles sejam plenamente conscientes de seu meio, mas também do papel que devem desempenhar nesse mesmo meio. A arte e a filosofia são uma possibilidade nas práticas educativas por serem ferramentas acessíveis que permitem aos alunos viverem a experiência emocional do outro, mas também de si próprio.

\section{REFERÊNCIAS}

ARENDT, H. (1989). La crise de la culture: huit exercices de pensée politique. Paris. Gallimard.

BORDEAUX, M-C. L'éducation artistique et culturelle à l'épreuve de ses modèles dans Les artistes à l'école: fin d'une illusion ou utopie en devenir? Quaderni. Editions de la maison des sciences de l'Homme. pp. 27- 35, 2017.

BORDEAUX, M-C; Kerlan A. L'évaluation des "effets" de l'éducation artistique et culturelle. Etude méthodologique et épistémologique. Relatório final, 2016.

CHIROUTER, E. L'enfant, la littérature et la philosophie. Paris. L'Harmattan, 2015. 
DEWEY, J. L'art comme expérience. Paris. Gallimard, 1934.

DUCHAMP, M. "C'est le regardeur qui fait l'œuvre" Marcel Duchamp. Conferência sobre a obra "Fonte", 1965.

FILIOD, J-P. Le sensible comme connaissance, évaluer les pratiques au seuil de l'expérience. Relatório final, 2014, p.10, 2014.

KERLAN, A.; ROBERT, A. Enfants et artistes ensemble, recomposition de l'enfance, refondation des politiques de l'enfance. PUN, Editions Universitaires de Lorraine, Questions d'éducation et de formation, 2016.

KERLAN, A.; SIMARD, D. Ricoeur et la question éducative. Presses de l'Université Laval, ENS de Lyon, 2011..

MARZANO, M. La philosophie du corps. Paris: Presses Universitaires de France, 2007.

MERLE, L. Le livre d'artiste pour enfants: une approche esthétique et socioculturelle de l'enfance. Tese de doutorado en Ciências da Educação, sob orientação de Alain Kerlan, Université de Lyon 2, 421 p, 2017.

NUSSBAUM, M. Les émotions démocratiques. Comment former le citoyen du XXle siècle? Coleção Climats. Flammarion, 2011.

RICOEUR, P. Soi-même comme un autre. Paris: Seuil, 1990.

RICOEUR, P. Temps et récit. Volume 1. L'intrigue et le récit historique. Paris: Seuil, 1991.

TOZZI, M. L'éveil de la pensée réflexive à l'école primaire. Paris: Hachette Education, 2001.

WINNICOTT, DW. (2002). Jeu et réalité: I'espace potentiel. Paris.Gallimard.

ZASK, J. Pratiques artistiques et conduites démocratiques. Noesis. Art et politique 11, 2007.

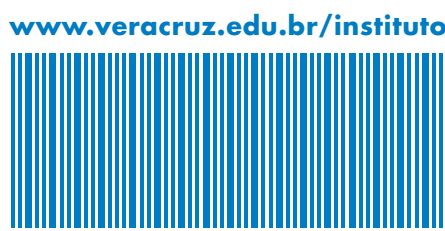

